\title{
Phosphorylation and inactivation of glycogen synthase kinase-3 by soluble kit ligand in mouse oocytes during early follicular development
}

\author{
Lian Liu ${ }^{1,6}$, Singareddy Rajareddy ${ }^{1}$, Pradeep Reddy ${ }^{1}$, Krishna Jagarlamudi ${ }^{1}$, Chun Du ${ }^{1}$, \\ Yan Shen ${ }^{1}$, Yongzhi Guo ${ }^{1}$, Karin Boman ${ }^{2}$, Eva Lundin ${ }^{3}$, Ulrika Ottander ${ }^{4}$, Gunnar Selstam ${ }^{5}$ \\ and Kui Liu ${ }^{1}$ \\ ${ }^{1}$ Departments of Medical Biochemistry and Biophysics, ${ }^{2}$ Radiation Sciences, ${ }^{3}$ Medical Biosciences/Pathology, ${ }^{4}$ Clinical Science/Obstetrics and Gynecology, ${ }^{5}$ Molecular Biology, Umeå \\ University, SE-901 87 Umeå, Sweden \\ ${ }^{6}$ Qilu Hospital, Shandong University, Jinan, 250012 Shandong, China
}

(Requests for offprints should be addressed to K Liu; Email: kui.liu@medchem.umu.se)

(L Liu, S Rajareddy and P Reddy contributed equally to this work)

\begin{abstract}
Communication between mammalian oocytes and their surrounding granulosa cells through the Kit-Kit ligand (KL, or stem cell factor, SCF) system has been shown to be crucial for follicular development. Our previous studies (Reddy et al. 2005, Liu et al. 2006) have indicated that the intra-oocyte KL-Kit-PI3 kinase (PI3K)-Akt-Foxo3a cascade may play an important role in follicular activation and early development. In the present study, using in situ hybridization and in vitro culture of growing oocytes from 8-day-old postnatal mice, we have demonstrated that another Akt substrate, glycogen synthase kinase-3 (GSK-3), is expressed in growing oocytes. Also, treatment of cultured mouse oocytes with soluble KL not only leads to increased Akt kinase activity in the oocytes, which can phosphorylate recombinant GSK-3 in vitro, but also leads to phosphorylation of oocyte GSK-3 $\alpha$ and GSK-3 $\beta$, which can result in the inactivation of GSK-3 function in oocytes. In addition, we have shown that the regulation of GSK- $3 \alpha$ and GSK-3 $\beta$ in cultured oocytes by soluble KL is accomplished through PI3K, since the PI3K-specific inhibitor LY294002 completely abolished the KL-induced phosphorylation of GSK-3 $\alpha$ and GSK-3 $\beta$. Moreover, blockage of the Kit signaling pathway by a Kit function-blocking antibody, ACK2, resulted in reduced phosphorylation of GSK-3. Taken together, our data suggest that the cascade from granulosa cell-derived KL to Kit-PI3K-Akt-GSK-3 in oocytes may take part in regulation of oocyte growth and early ovarian follicular development.
\end{abstract}

Journal of Molecular Endocrinology (2007) 38, 137-146

\section{Introduction}

In mammals, the ovary is a heterogeneous organ containing follicles and copora lutea at various stages of development. Each follicle contains an oocyte that is surrounded by granulosa cells. In order to produce mature oocytes, follicles are activated from the pool of dormant primordial follicles, and develop through primary and secondary stages before acquiring an antral cavity. At the antral stage, most follicles undergo atretic degeneration, whereas a few of them grow further and reach the preovulatory stage under the cyclic gonadotropin stimulation that occurs after puberty. In response to preovulatory surges of gonadotropin during each reproductive cycle, the dominant Graafian follicle ovulates to release the mature oocyte for fertilization, whereas the remnant follicle undergoes luteinization to become the corpus luteum (for reviews, see Elvin \& Matzuk 1998, McGee \& Hsueh
2000, Matzuk et al. 2002, Richards et al. 2002, Vanderhyden 2002).

The postnatal ovary is mainly populated by primordial follicles, each composed of a meiotically arrested primary oocyte enclosed within several flattened pregranulosa cells. During follicular activation and early development, oocytes and granulosa cells grow coordinately but not simultaneously (Wassarman \& Albertini 1994). In the mouse, oocytes undergo rapid growth with an approximately 300-fold increase in volume before the formation of a follicular antrum (Wassarman \& Albertini 1994). Although somatic cells grow from a single layer of a few flattened pregranulosa cells to three layers of cuboidal granulosa cells by the time the oocyte has completed its growth, by far the greatest amount of granulosa cell proliferation and differentiation occurs after the oocyte has stopped growing (Wassarman \& Albertini 1994). 
The growth and meiotic regulation of oocytes are dependent on granulosa cells. At the same time, oocytes also secrete various factors which play key roles in folliculogenesis (Wassarman \& Albertini 1994, Elvin \& Matzuk 1998, McGee \& Hsueh 2000, Vanderhyden 2002). The bidirectional communication between oocytes and granulosa cells is essential for follicular development, which maintains female reproduction (Wassarman \& Albertini 1994, Eppig 2001, Nilsson \& Skinner 2001, Matzuk et al. 2002, Vanderhyden 2002, Albertini \& Barrett 2003). The Kit-Kit ligand (KL, or stem cell factor, SCF) system is known to play a role in the communication between oocytes and granulosa cells. Kit is a receptor protein tyrosine kinase (RPTK) that can be activated by its only known ligand KL (Besmer et al. 1993). During early folliculogenesis in mice, Kit is present in oocytes at all stages of the follicle (Manova et al. 1990, Orr-Urtreger et al. 1990, Horie et al. 1991, Driancourt et al. 2000), and KL is produced by the surrounding granulosa cells (Manova et al. 1993, Laitinen et al. 1995, Ismail et al. 1996, Vanderhyden 2002). The functions of KL and Kit in follicular development have been extensively investigated for decades, and several lines of evidence have indicated that growth of the ovarian follicle is dependent on KL-Kit signaling at a time when functional folliclestimulating hormone (FSH) receptors are not yet expressed in the mouse ovary (for some recent reviews, see: Driancourt et al. 2000, Eppig 2001, Nilsson \& Skinner 2001, Vanderhyden 2002, Albertini \& Barrett 2003).

The KL-Kit downstream signaling pathways in mammalian oocytes are largely unknown. Our previous report has suggested that in mouse and rat oocytes, the action of soluble KL on oocytesurface Kit causes the activation of a signaling cascade involving KL-Kit-PI3 kinase (PI3K)-AktFoxo3a (Reddy et al. 2005). Except for oocyte Foxo3a, the function of which is to suppress oocyte growth and follicular development (Liu et al. 2006), the identities of other Akt substrates that are regulated by KL-Kit in oocytes are not yet known. In the present study, we have investigated the KL-mediated regulation of another Akt substrate, GSK-3. GSK-3 is a serine/threonine kinase involved in several different signaling pathways. Two forms of GSK-3, designated GSK-3 $\alpha$ and GSK-3 $\beta$, have been identified, which are encoded by two distinct genes (Welsh et al. 1996). GSK-3 was initially identified as a kinase that phosphorylates and inactivates glycogen synthase (GS) and regulates glycogen synthesis in response to insulin (Welsh et al. 1996). Later on, GSK-3 also became recognized as a critical downstream element of the PI3K and the Wnt signaling pathways (Cross et al. 1995, Nusse 1997, Srivastava \& Pandey 1998). Moreover, GSK-3 $\beta$ has been shown to regulate cyclin D1 proteolysis and subcellular localization in mouse fibroblasts (Diehl et al. 1998). GSK-3 has also been implicated in Alzheimer's disease (Ferrer et al. 2005). In the present study, we have investigated how GSK-3 $\alpha$ and GSK-3 $\beta$ are regulated by soluble KL in cultured growing mouse oocytes, and suggest that GSK-3 may play a role in oocyte growth and early follicular development.

\section{Materials and methods}

\section{Reagents, antibodies, and immunological detection methods}

Restriction enzymes, 4-nitro blue tetrazolium chloride, 5-bromo-4-chloro-3-indolyl-phosphate, anti-digoxigenin-AP Fab fragments, and the Dig RNA labeling kit for synthesis of riboprobes for in situ hybridization were obtained from Roche Molecular Biochemicals (Roche Diagnostics Scandinavia AB). The Kit-neutralizing antibody ACK2 was purchased from eBiosciences (San Diego, CA, USA). The PI3K inhibitor (LY294002) and recombinant soluble mouse $\mathrm{KL}$ were from EMD Biosciences (San Diego, CA, USA). The Akt kinase assay kit and the rabbit polyclonal antibodies against phospho-Akt (serine 473), phospho-GSK-3 $\alpha / \beta$ (serine 21/9), phospho-GS (serine 641), GSK-3 $\alpha$, GSK-3 $\beta$, phospho-p70S6 kinase (threonine 389), and phosphomTOR (serine 2481) were obtained from Cell Signaling Technologies (Beverly, MA, USA). Mouse monoclonal antibody against $\beta$-actin was purchased from SigmaAldrich (Sigma-Aldrich Sweden AB). Anti-mouse and anti-rabbit secondary antibodies coupled to horseradish peroxidase (HRP) were purchased from BioRad. Western blot analyses were carried out according to the instructions for antibodies from the manufacturers, and the results were visualized using the ECL Plus Western Blotting Detection System (Amersham Biosciences).

\section{Animals}

C57BL/6 mice were obtained from Bomholtgaard Breeding and Research Center (Boommice, Ry, Denmark). The animals were housed under controlled environmental conditions with access to water and food ad libitum. Illumination was on between 0600 and $1800 \mathrm{~h}$. Experimental protocols were approved by the regional ethical committee of Umeå University.

\section{Isolation of growing oocytes from postnatal mouse ovaries}

To obtain mouse oocytes at their active growing stage, we used postnatal day 8 female C57BL/ 6 mouse ovaries based on earlier literature (Wassarman \& Albertini 
1994, Matzuk et al. 2002). Postnatal day 8 ovaries are predominantly populated by primordial and primary follicles, and no follicular antrum is seen. Thus, the oocytes we isolated from postnatal 8-day-old mice represent a population of oocytes that are in their active growing period.

The oocytes were isolated as described previously (Reddy et al. 2005). Briefly, 8-day-old female mice were sacrificed by decapitation, and the ovaries were dissected free of fat and connective tissue under the microscope. The ovaries were then minced with a pair of dissection scissors before being incubated in $0.05 \%$ collagenase dissolved in Dulbecco's modified Eagle's medium-F12 (DMEM/F12, Life Technologies Inc.) supplemented with $4 \mathrm{mg} / \mathrm{ml}$ BSA and 100 units $/ \mathrm{ml}$ penicillin and $100 \mu \mathrm{g} / \mathrm{ml}$ streptomycin, with frequent agitation and pipetting. After the tissues were digested by collagenase over a period of 45-60 min, EDTA was added to the mixture to a final concentration of $40 \mathrm{mM}$, and the mixture was incubated at $37^{\circ} \mathrm{C}$ with frequent pipetting for another 15-20 min until clusters of granulosa cells were dispersed into individual cells. The mixture of granulosa cells, blood cells, and oocytes was then washed once and cultured in a $6 \mathrm{~cm}$ tissue culture dish with the above-mentioned serum-free DMEM/F12 medium for 12-16 h, to allow the granulosa cells to attach to the plastic. The unattached oocytes were then recovered by collection of the supernatant and centrifugation (1800 r.p.m., 5 min at room temperature). Oocytes obtained by this method were basically free of contamination with granulosa cells. The sizes of oocytes we obtained as measured by microscopy were in the $15-41 \mu \mathrm{m}$ range, representing a population of growing oocytes. Equal volumes of oocytes were aliquoted into wells of a 24-well plate (approximately 500 oocytes per well) in $1 \mathrm{ml}$ DMEM/ F-12 medium and maintained at $37^{\circ} \mathrm{C}$ in a humidified atmosphere of $5 \% \mathrm{CO}_{2}$ in air.

\section{Stimulation of isolated oocytes with KL}

After starvation for 4-6 h in serum-free DMEM/F-12 medium as mentioned above, oocytes in 24-well plates (see above) were treated for $2,5,10$, and 30 min or for 4$16 \mathrm{~h}$ with $150 \mathrm{ng} / \mathrm{ml}$ recombinant soluble KL in the same medium. The concentration and the stimulation time with the soluble KL that we adopted are the commonly used conditions for other cell types when activating the Kit receptor tyrosine kinase in vitro (Kissel et al. 2000, Voytyuk et al. 2003, Reddy et al. 2005). For combined treatment with KL and PI3K inhibitor LY294002, the oocytes were pretreated for $1 \mathrm{~h}$ with LY294002 at a concentration of $25 \mu \mathrm{M}$ (the concentration and duration are well known to suppress PI3K activity in many other cell types; Vlahos et al. 1994), and this was followed by stimulation with KL. After KL stimulation, the 24-well plate was chilled quickly on ice. The oocytes were collected in eppendorf tubes, washed once with cold PBS, and lysed in a buffer containing $50 \mathrm{mM}$ Tris-HCl (pH 8.0), $120 \mathrm{mM} \mathrm{NaCl}, 20 \mathrm{mM} \mathrm{NaF}, 20 \mathrm{mM}$ $\beta$-glycerophosphate, $1 \mathrm{mM}$ EDTA, $6 \mathrm{mM}$ EGTA (pH $8 \cdot 0), 1 \%$ NP-40, $1 \mathrm{mM}$ DTT, $5 \mathrm{mM}$ benzamidine, $1 \mathrm{mM}$ PMSF, $250 \mu \mathrm{M}$ sodium vandadate, $2 \mu \mathrm{g} / \mathrm{ml}$ aprotinin, $10 \mu \mathrm{g} / \mathrm{ml}$ leupeptin, and $1 \mu \mathrm{g} / \mathrm{ml}$ pepstatin for $20 \mathrm{~min}$ on ice with frequent vortexing. The lysates were collected by centrifugation at 14000 r.p.m. for $20 \mathrm{~min}$ at $4^{\circ} \mathrm{C}$, and used for further analysis by Western blot.

\section{Akt kinase assay}

The Akt kinase assay was performed using the kinase assay kit from Cell Signaling Technologies (Beverly, MA, USA). Briefly, Akt was precipitated using an immobilized monoclonal antibody that preferentially recognizes phosphorylated Akt at serine 473. After washing, adenosine-5'-triphosphate (ATP) and recombinant GSK-3 were added to the reaction mixture and the kinase reaction was run at $30^{\circ} \mathrm{C}$ for $30 \mathrm{~min}$. The reaction mixture was then heated at $95^{\circ} \mathrm{C}$ for 5 min before being run on an SDS-PAGE gel and blotted against an antibody that recognizes phosphorylated GSK-3.

\section{Synthesis of GSK-3 $\alpha$ and GSK-3 $\beta$ RNA probe}

The murine GSK-3 $\alpha$ cDNA was kindly provided by Dr Dario Alessi (University of Dundee, UK). A fragment of mouse GSK-3 $\beta$ cDNA (nucleotides 1033-1627 of BC 060743) was obtained by RT-PCR from mouse ovarian RNA and was subcloned into the pCRII-TOPO vector (Invitrogen). Before transcription, plasmids were linearized such that antisense or sense RNA probes could be obtained. The riboprobes used for in situ hybridization were labeled with digoxigenin-labeled UTP using the Dig RNA labeling kit (Roche Diagnostics).

\section{In situ hybridization}

Mice were sacrificed by decapitation, and the ovaries were collected and frozen in Tissue-Tec OCT compound (Miles, Elkhart, IL, USA) before being stored at $-80^{\circ} \mathrm{C}$ for further use. The in situ hybridization was performed as described (Schaeren-Wiemers \& Gerfin-Moser 1993). The hybridization signals appear dark brown or black. To monitor background levels and specificity of hybridization, the sense-strand probes were used.

\section{Statistical analysis}

All experiments were repeated at least three times, and representative data are shown. For experiments 
involving Western blot analysis of proteins from cultured oocytes, typically 25-30 animals were used each time and their oocytes were pooled. Approximately 500 oocytes were used per lane. In addition, normalized values from Western blot (determined by densitometric analysis with the mean \pm s.D. from three independent experiments) were used. In most cases, the intensity of a band of the highest density in a Western blot was defined as $1 \cdot 0$, and from this value all other values on the same blot were calculated. Note that relative density representing the level of expression of a protein is only comparable with other time points or treatments within the same experiment, and that relative densities are not useful for comparisons between different proteins. Data were analyzed with ANOVA. Differences among groups were calculated with Tukey's multiple-comparison test, and a difference was considered to be significant if $P<0 \cdot 05$.

\section{Results}

\section{Mouse oocyte-derived Akt can phosphorylate recombinant GSK-3 in vitro}

In order to determine whether oocyte-derived Akt could phosphorylate GSK-3, we used a recombinant GSK-3 $\alpha / \beta$ crosstide, which corresponds to residues surrounding the Akt phosphorylating serine 21 and serine 9 in GSK- $3 \alpha$ and GSK-3 $\beta$ respectively (CGPKGPGRRGRRRTSSFAEG), and which was fused to the $\mathrm{N}$ terminus of paramyosin (Cell Signaling Technologies, Beverly, MA, USA). ATP was used to provide the phosphate group. An immobilized mouse monoclonal antibody to Akt (1G1), which binds preferentially to Akt that has been phosphorylated at serine 473, was used to precipitate active Akt from oocyte lysates.

As shown in Fig. 1A ('a'), immunoprecipitated active Akt was capable of phosphorylating the recombinant GSK-3 in vitro. Treatment of cultured mouse oocytes from ovaries of 8-day-old mice with $150 \mathrm{ng} / \mathrm{ml}$ soluble $\mathrm{KL}$ activated the Akt kinase activity further, and gave elevated levels of phosphorylated recombinant GSK-3, which was marginally increased at $2 \mathrm{~min}$ of KL treatment (approximately 1.8-fold; Fig. 1A ('a', lane 2 ) and B), and significantly increased at $5 \mathrm{~min}$ of $\mathrm{KL}$ treatment (approximately 3-fold; Fig. 1A ('b', lane 3) and B) relative to the basal level of Akt activity in untreated oocytes. In accordance with the increased levels of phosphorylated GSK-3, levels of phosphorylated Akt significantly increased after 2 and 5 min of KL treatment (Fig. 1A ('b')).

\section{Expression of GSK-3 in postnatal mouse ovaries}

We then studied whether GSK-3 is expressed in postnatal mouse ovaries and oocytes by performing
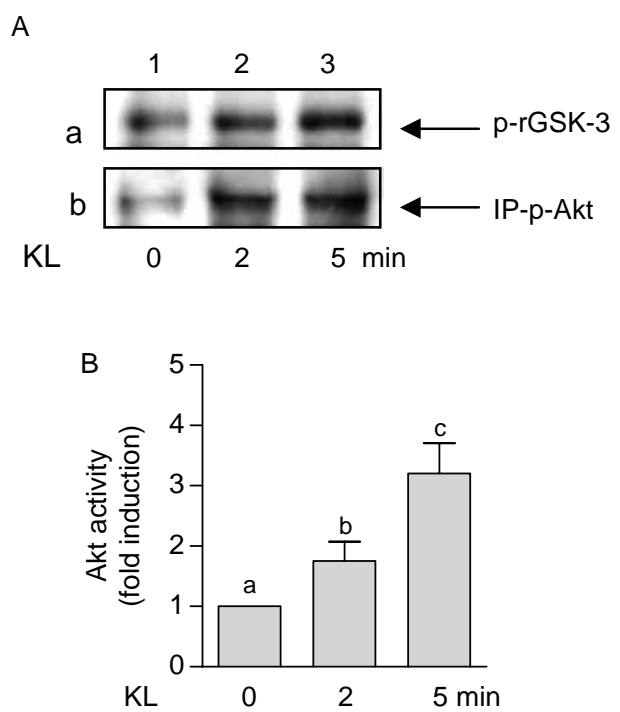

Figure $1 \mathrm{KL}$-mediated regulation of Akt kinase activities in mouse oocytes. Oocytes were isolated from 8-day-old mice, starved, and stimulated with $150 \mathrm{ng} / \mathrm{ml} \mathrm{KL}$ for 2 and 5 min. Phosphorylated Akt was immunoprecipitated from oocyte lysates and an Akt kinase assay was performed using recombinant GSK as Akt substrate, as described in Materials and methods. Both Akt kinase activities (p-rGSK-3) ((A) 'a') and the amount of immunoprecipitated phosphorylated Akt (IP-P-Akt) ((A) 'b') are shown. Normalized values (mean \pm S.D.) for changes in Akt kinase activity obtained from four independent experiments are also shown (B). Small letters $(\mathrm{a}, \mathrm{b}$, and $\mathrm{c})$ indicate significant differences $(P<0.05)$. p-rGSK-3, phosphorylated recombinant GSK-3; IP-p-Akt, immunoprecipitated phosphorylated Akt.

in situ hybridization using postnatal mouse ovaries at day 8. As shown in Fig. 2A, GSK-3 $\beta$ is generally expressed in all ovarian cell types at this stage of development. In primary follicles, GSK- $3 \beta$ mRNA is expressed in both oocytes (Fig. 2A, white arrow) and granulosa cells (Fig. 2A, black arrow). In addition, GSK$3 \beta$ mRNA was also found to be expressed in the cytoplasm of oocytes of primordial follicles (Fig. 2B, arrows). As a negative control, sections hybridized with a sense probe of GSK- $3 \beta$ showed basically no hybridization signal (Fig. 2C). In addition, the expression pattern of GSK- $3 \alpha$ mRNA was found to be identical to that of GSK-3 $\beta$ (not shown).

\section{KL treatment leads to phosphorylation of GSK-3 $\alpha$ and GSK-3 $\beta$ through the PI3K pathway in cultured growing mouse oocytes}

Having shown that Akt activity is enhanced by stimulation with soluble $\mathrm{KL}$, we then investigated whether KL may also regulate GSK-3 via its receptor Kit on the oocyte surface. As the phosphorylation of serine 21 in GSK- $3 \alpha$ and serine 9 in GSK- $3 \beta$ by Akt leads to inactivation of GSK-3 activities, we used the levels of 

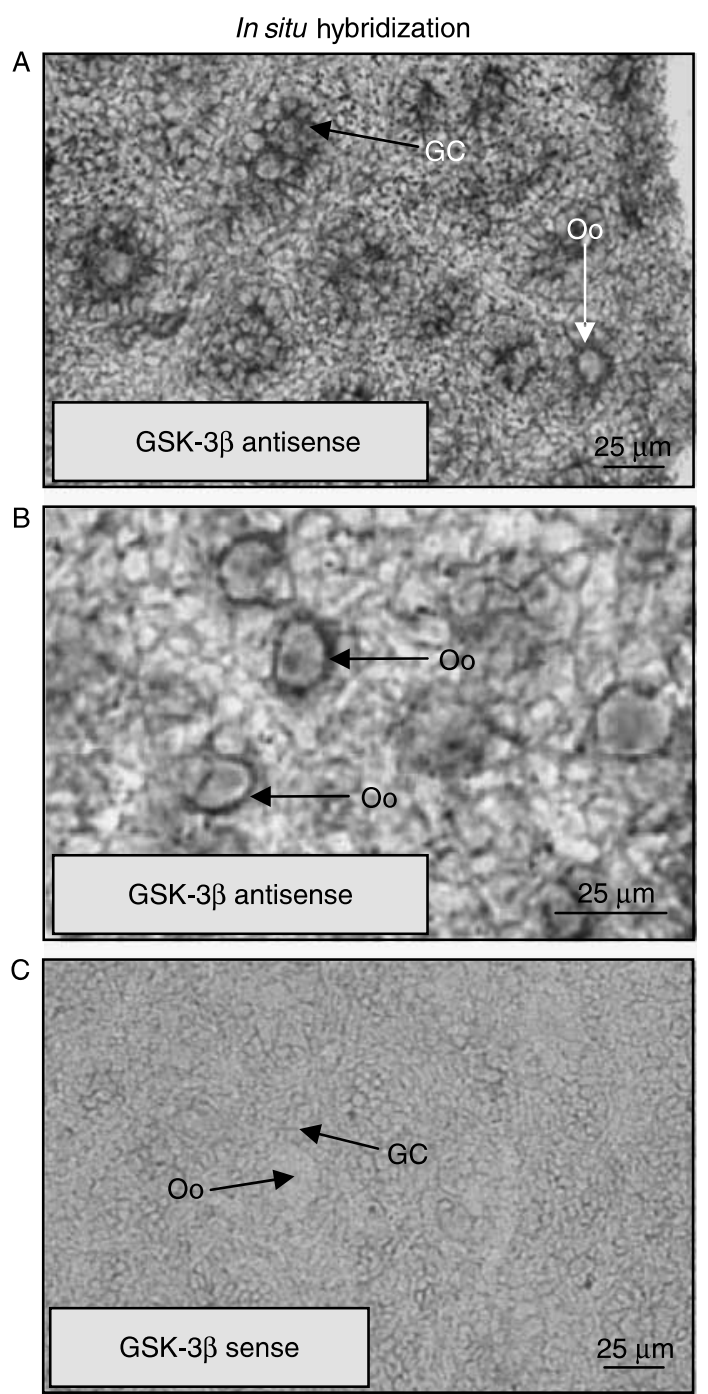

Figure 2 Localization of GSK-3 $\beta$ mRNA in ovaries of 8-day-old mice by in situ hybridization. In situ hybridization was performed as described in Materials and methods. The hybridization signals appear dark brown or black. The horizontal black bars represent $25 \mu \mathrm{m}$. Experiments were repeated at least three times and representative results are shown. $((A)$ and $(B))$ GSK-3 $\beta$ mRNA expression in primary follicles (A) and in primordial follicles (B). (C) A section that was hybridized with the sense probe of GSK-3 $\beta$ as a negative control. Oo, oocyte; GC, granulosa cells.

phosphorylation of GSK- $3 \alpha$ and GSK-3 $\beta$ at these residues to evaluate the activity levels of GSK-3. To reduce the basal activity of Akt and other kinases, we first starved the isolated mouse oocytes in serum-free DMEM/F-12 medium. The oocytes were then stimulated for various periods of time ranging from 2 to 30 min with recombinant soluble mouse KL at a concentration of $150 \mathrm{ng} / \mathrm{ml}$. To study the possible role of PI3K in the regulation of GSK-3 by KL, we also pretreated the starved oocytes with a PI3K-specific inhibitor LY294002 for $1 \mathrm{~h}$ before the KL stimulation.
As shown in Fig. 3A, treatment of isolated 8-day-old mouse oocytes with KL for 2 min resulted in significantly elevated levels of phosphorylated GSK-3 $\alpha$ and GSK-3 $\beta$ (Fig. 3A ('a' and 'b', lane 2 vs lane 1)), indicating that GSK-3 is immediately regulated by KL. In addition, KL induced a sustained phosphorylation of GSK- $3 \alpha$ and GSK- $3 \beta$ during an experimental time range of 2-30 min (Fig. 3A, lanes 2-5).

A
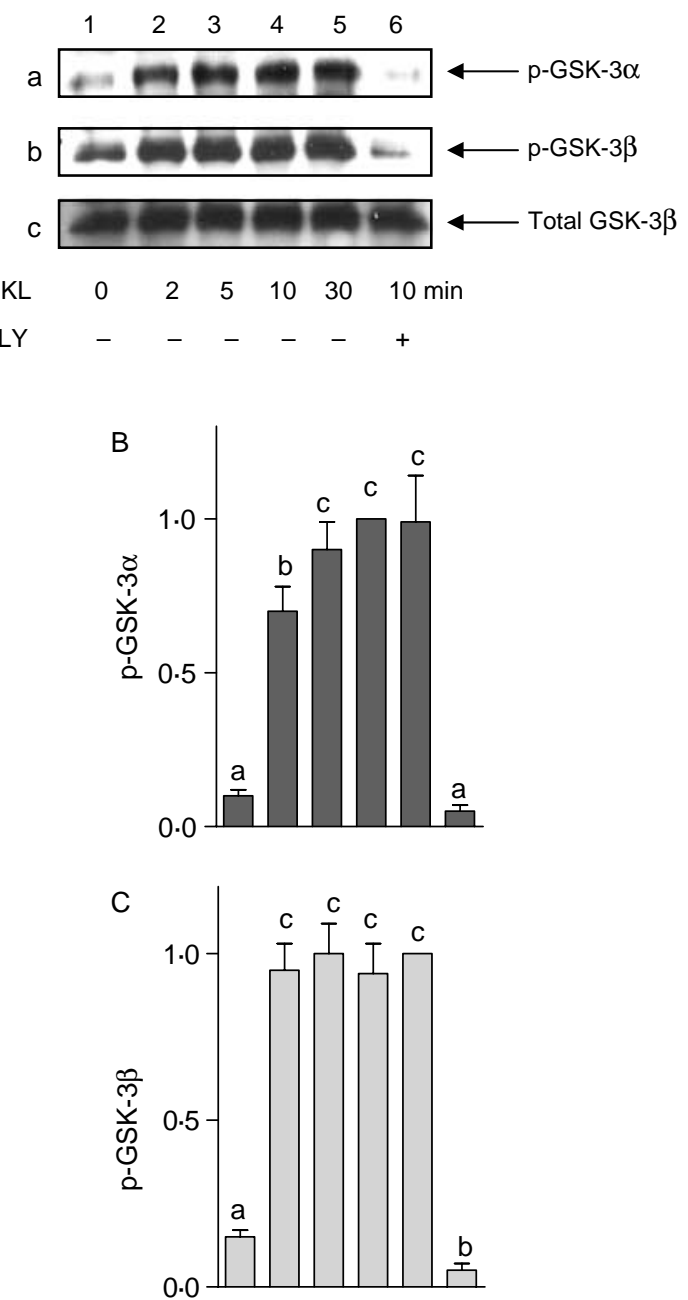

$$
\begin{array}{llllllll}
\mathrm{KL} & 0 & 2 & 5 & 10 & 30 & 10 & \mathrm{~min} \\
\mathrm{LY} & - & - & - & - & - & +
\end{array}
$$

Figure 3 Short-term KL treatment leads to phosphorylation of GSK-3 $\alpha$ and GSK-3 $\beta$ in oocytes isolated from 8-day-old mice. Oocytes were isolated from 8-day-old mice, starved, and stimulated with $150 \mathrm{ng} / \mathrm{ml}$ recombinant soluble $\mathrm{KL}$ for 2, 5, 10, and 30 min, or pretreated with the PI3K inhibitor LY294002 (LY) for $1 \mathrm{~h}$ prior to treatment with $\mathrm{KL}$ for $10 \mathrm{~min}$, before being lysed for Western blot analysis as described in Materials and methods. (A) Levels of phosphorylated GSK- $3 \alpha$ (a), GSK-3 $\beta$ (b) and total GSK-3 $\beta$ (c) at different time points of $K L$ stimulation. (B and $C$ ) Relative levels of phosphorylated GSK-3 $\alpha$ and GSK-3 $\beta$ respectively. Small letters $(a, b$, and $c)$ indicate significant differences $(P<0 \cdot 05)$. 
Pretreatment of oocytes with the PI3K-specific inhibitor LY294002 almost completely abolished the phosphorylation of both GSK-3 $\alpha$ and GSK-3 $\beta$ (Fig. 3A ('a' and ' $\mathrm{b}$ ', lane 6)), indicating that both GSK-3 $\alpha$ and GSK-3 $\beta$ are phosphorylated through the PI3K. As internal controls, total levels of GSK-3 $\beta$ at different time points were found to be basically equal (Fig. 3A $($ ' $c$ ')), indicating that the significant changes in levels of phosphorylated GSK-3 $\alpha$ and GSK-3 $\beta$ were not caused by uneven loading of oocyte lysates. Quantification of changes in phosphorylated GSK- $3 \alpha$ and GSK- $3 \beta$ levels is shown in Fig. 3B and $\mathrm{C}$.

The rapid (2-30 min) stimulation of GSK-3 phosphorylation by soluble KL in cultured mouse oocytes indicates that oocyte GSK-3 may be regulated in vivo by KL secreted by granulosa cells. However, the short-term stimulation protocol may not be a good reflection of the in vivo situation, in which KL affects the activities of oocyte GSK-3. Thus, we also investigated how oocyte GSK-3 may be regulated by KL when the oocytes were treated for longer times. As shown in Fig. 4A ('a' and 'b', lanes 2-5 vs lane 1), treatment of cultured 8-day-old oocytes with $\mathrm{KL}$ for $4-16 \mathrm{~h}$ led to significantly elevated and sustained phosphorylation levels of both GSK-3 $\alpha$ and GSK-3 $\beta$ in the oocytes, indicating that both GSK-3 $\alpha$ and GSK-3 $\beta$ were inactivated by longer-term KL treatment. The p-GSK-3 $\beta$ level at $16 \mathrm{~h}$ after $\mathrm{KL}$ treatment, however, was somewhat reduced as compared with $12 \mathrm{~h}$ after KL treatment (Fig. 4A ('b', lane 5 vs lane 4)). Total GSK-3 $\beta$ levels in the same Western blot are shown as an internal control for equal loading (Fig. 4A,C). Quantification of changes in phosphorylated GSK- $3 \alpha$ and GSK-3 $\beta$ levels is also shown in Fig. 4B and C.

\section{Blockage of Kit signaling results in reduced GSK-3 phosphorylation}

Both GSK- $3 \alpha$ and GSK-3 $\beta$ were found to be phosphorylated via the KL-Kit-PI3K pathway, indicating that KL can lead to inactivation of GSK-3. To confirm this hypothesis, we also treated cultured mouse oocytes with a Kit function-blocking antibody, ACK2, and studied how blockage of the Kit signaling pathway would affect GSK-3 phosphorylation. As expected, incubation of cultured oocytes with $10 \mu \mathrm{g} / \mathrm{ml}$ ACK2 for 12 and $16 \mathrm{~h}$ significantly reduced the levels of phosphorylated GSK$3 \beta$ as compared with untreated oocytes, or oocytes treated for only $4 \mathrm{~h}$ (Fig. 5A ('a', lanes 3 and 4 vs lanes 1 and 2)). These results indicate that the KL-Kit signaling pathway is necessary to maintain GSK-3 in an inactivated form. Equal loading is shown by the levels of GSK$3 \beta$ in the same set of samples (Fig. 5A ('b')). Quantification of phosphorylated GSK-3 $\beta$ levels is shown in Fig. 5B. In addition, we have also measured the levels of phosphorylated GS as a possible GSK-3
A
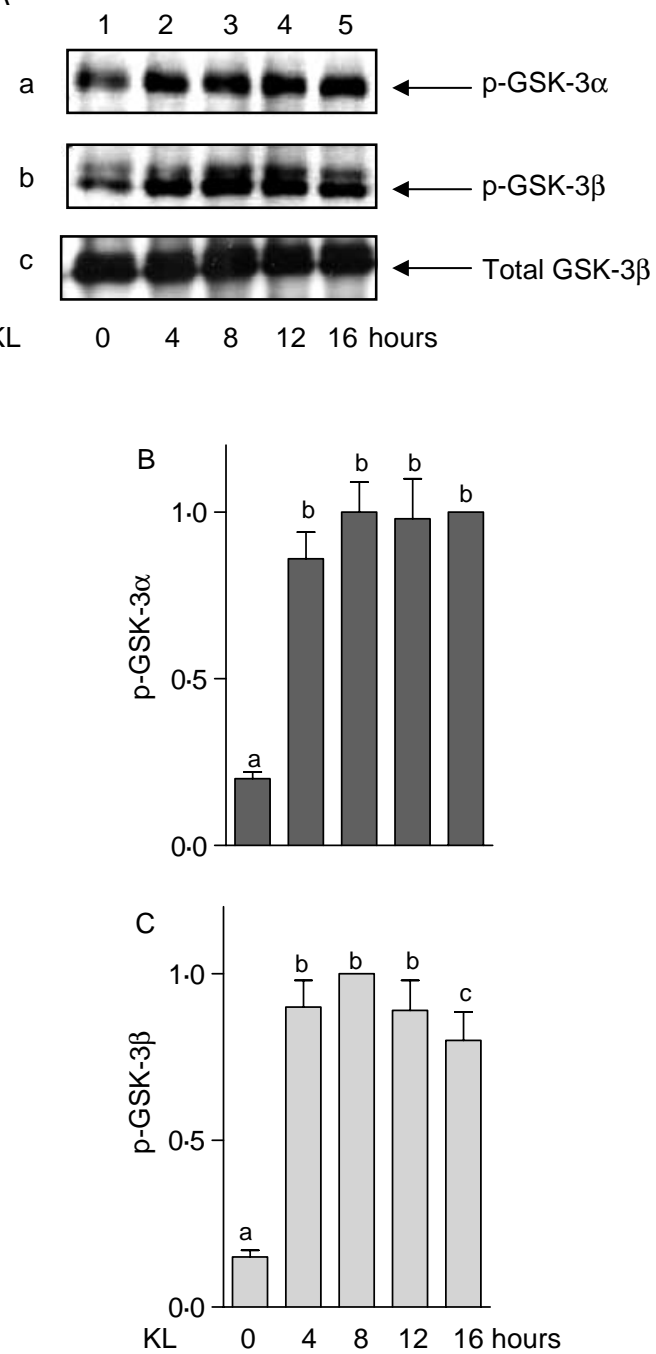

Figure 4 Long-term $\mathrm{KL}$ treatment leads to phosphorylation of GSK- $3 \alpha$ and GSK-3 $\beta$ in oocytes isolated from 8-day-old mice. Oocytes were isolated from 8-day-old mice, starved, and stimulated with $150 \mathrm{ng} / \mathrm{ml}$ recombinant soluble $\mathrm{KL}$ for 4, 8, 12, and $16 \mathrm{~h}$, and oocytes were lysed for Western blot analysis as described in Materials and methods. (A) Levels of phosphorylated GSK-3 $\alpha$ (a), GSK-3 $\beta$ (b), and total GSK-3 $\beta$ (c) at different times of $\mathrm{KL}$ stimulation. ((B) and (C)) Relative levels of phosphorylated GSK- $3 \alpha$ and GSK-3 $\beta$ respectively. Small letters $(a, b$, and $c)$ indicate significant differences $(P<0 \cdot 05)$.

substrate (Villar-Palasi \& Guinovart 1997) in the same experiment (see also next paragraph); however, the level of p-GS was not found to be significantly altered by the treatment with ACK2 (data not shown).

\section{Regulation of GS on stimulation with KL in mouse oocytes}

The next question to be answered was what the physiological significance of KL-Kit-induced GSK-3 
A
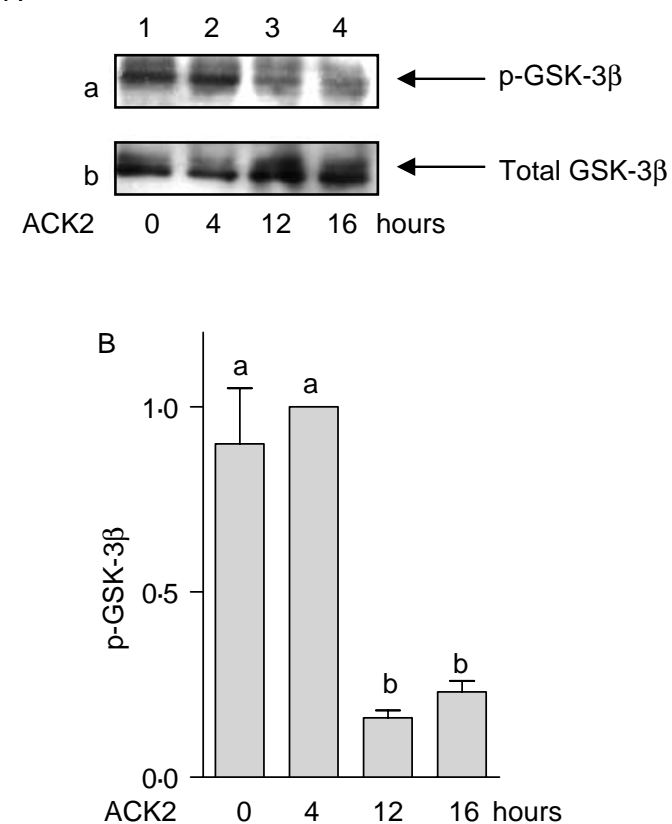

Figure 5 The Kit-blocking antibody ACK2 reduced the phosphorylation of GSK-3 $\beta$ in mouse oocytes. Oocytes were isolated from 8-day-old mice, starved, and treated with the Kit functionblocking antibody ACK2 $(10 \mu \mathrm{g} / \mathrm{ml})$ for 4,12 , and $16 \mathrm{~h}$, and the oocytes were then lysed for Western blot analysis as described in Materials and methods. (A) Levels of phosphorylated GSK-3 $\beta$ (a) and total GSK-3B (b). (B) Relative levels of phosphorylated GSK-3 $\beta$. Small letters ( $a$ and $b$ ) indicate significant differences $(P<0.05)$.

phosphorylation or functional inactivation is. GSK-3 is a serine/threonine kinase that can phosphorylate several downstream molecules, including GS, cyclin D1, Tau, and $\beta$-catenin (Welsh et al. 1996, Yost et al. 1996, Diehl et al. 1998, Johnson \& Stoothoff 2004). Among the many substrates of GSK-3, GS is a molecule that actively takes part in glycogen synthesis, and it may be of importance for energy storage during oocyte growth and resumption of meiosis. Interestingly, GS activity is also regulated by phosphorylation/dephosphorylation; upon phosphorylation of its serine 641 and other sites by GSK-3, GS is inactivated (Villar-Palasi \& Guinovart 1997). Thus, the phosphorylation/ inactivation of GSK-3 by KL is expected to lead to less-phosphorylated, more-active GS, which results in enhanced glycogen synthesis.

We hypothesized that KL may regulate glycogen metabolism in oocytes through the KL-Kit-PI3K-AktGSK-GS cascade. Therefore, we attempted to measure whether KL-mediated stimulation can lead to changes in the level of phosphorylated GS, which is a good indication of its activity. Using a similar experimental setup with cultured mouse oocytes, KL treatment was performed for 2-30 min (Fig. 6). No significant change in the level of phosphorylated GS was seen, however (Fig. 6A and $\mathrm{E}$ ), indicating that the phosphorylation state/activity of GS is not immediately affected by the KL-Kit inactivated GSK-3 in growing mouse oocytes.

Two molecules that control protein translation, p70S6 kinase (p70S6K) and mammalian target of rapamycin (mTOR), which are partially regulated by the PI3K pathway in other cell types and control the sizes of cells (Blume-Jensen \& Hunter 2001, Fingar et al. 2002), are also considered to be of importance in the control of oocyte growth during early follicular development. Thus, their activation by KL in vitro in cultured-growing mouse oocytes was also studied in this work. We found that the phosphorylation levels of both molecules (indicating their activation status) were not significantly affected by KL treatment of mouse oocytes in vitro (Fig. $6 \mathrm{~B}$ and $\mathrm{C}, \mathrm{F}$ and $\mathrm{G}$ ), indicating that their activities are not regulated by KL. Moreover, pretreatment of oocytes with the PI3K inhibitor LY294002 did not lead to any change in the phosphorylation levels of p70S6K and mTOR (data not shown). These results suggest that in oocytes, the activation of both p70S6K and mTOR was not regulated by the KL-Kit-PI3K pathway. Equal loading of the gels was confirmed by the $\beta$-actin levels in the same Western blot (Fig. 6D).

\section{Discussion}

During the past two decades, the essential roles of KL-Kit in mammalian oogenesis and follicular development have been demonstrated using both in vitro and in vivo approaches, including the use of naturally occurring or induced Kit or KL mutant mice (for some papers and reviews, see: Besmer et al. 1993, Kissel et al. 2000, Eppig 2001, Nilsson \& Skinner 2001, Vanderhyden 2002). However, the Kit downstream signaling pathways in mammalian oocytes remain largely unknown. Our previous report demonstrated that in mice and rats, recombinant soluble KL can activate the PI3K pathway of oocytes in vitro, subsequently leading to the activation of Akt and suppression of Foxo3a (Reddy et al. 2005), and oocyte Foxo3a has a functional role in suppressing oocyte growth and follicular development (Liu et al. 2006). Therefore, we suggested that the KL-Kit-PI3K-AktFoxo3a pathway in oocytes is regulated by the surrounding granulosa cells, and that this pathway may play roles in the control of oocyte growth and follicular development (Reddy et al. 2005, Liu 2006, Liu et al. 2006).

In the present study, we report for the first time that KL can also lead to phosphorylation and possibly inactivation of GSK- $3 \alpha$ and GSK-3 $\beta$ in mammalian oocytes. In addition, we have demonstrated that phosphorylation of GSK-3 is achieved through the PI3K pathway, as a specific PI3K inhibitor, LY294002, can completely abolish KL-induced GSK-3 phosphorylation. 

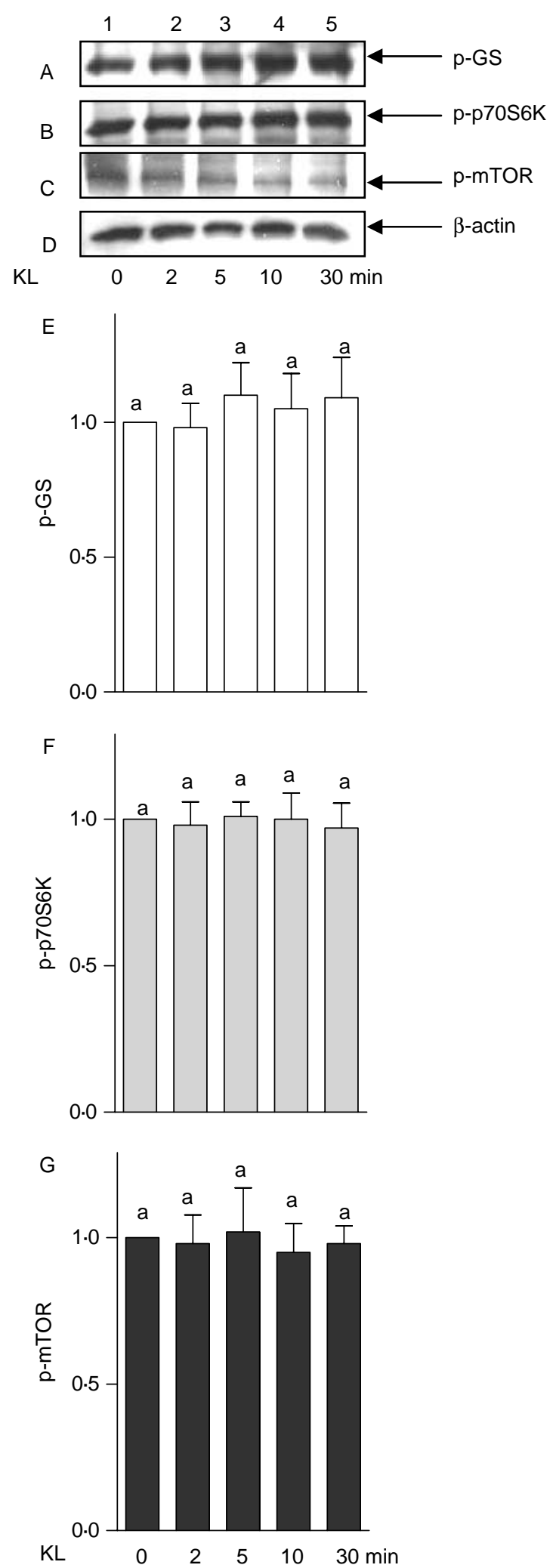

To further confirm that the inactivation of GSK-3 occurred through the KL-Kit signaling pathway, we blocked Kit function on the oocyte surface with a Kitneutralizing antibody, ACK2 (Yoshida et al. 1997). Our results showed that when the Kit signaling pathway was blocked, the phosphorylation/inactivation state of GSK-3 was reduced. Therefore, we conclude that granulosa cell-derived KL can regulate the activation state of GSK-3 in oocytes through the KL-Kit-PI3K-Akt pathway.

GSK-3 is a kinase that has been found to phosphorylate and inactivate GS thereby regulating glycogen synthesis (Welsh et al. 1996). However, in the present study, we found that although KL can rapidly inactivate both GSK- $3 \alpha$ and GSK-3 $\beta$, it does not regulate the activation state of GS in cultured mouse oocytes, indicating that a more complex regulation mechanism is involved. We assume that substrates of GSK-3 in growing mouse oocytes may be different from those in somatic cells or cancer cells, which are still unknown at this stage. For example, apart from GS, GSK-3 also has other substrates, including $\beta$-catenin and cyclin D1 (Yost et al. 1996, Diehl et al. 1998). $\beta$-Catenin is a key downstream effector in the Wnt signaling pathway, which has been implicated in early embryonic development and tumorigenesis (Cadigan \& Nusse 1997, Wodarz \& Nusse 1998, Polakis 1999). GSK-3 $\beta$ may destabilize $\beta$-catenin by phosphorylating it at serine 33, serine 37, and threonine 41 (Yost et al. 1996). Cyclin D1 regulates the activities of cyclin-dependent kinases (Cdk), and thus takes part in the regulation of cell-cycle progression. GSK-3 $\beta$ is known to phosphorylate cyclin D1 on its threonine 286 and trigger rapid proteolytic turnover of cyclin D1 in mouse fibroblasts (Diehl et al. 1998). In order to investigate the molecules downstream of GSK-3 in growing mouse oocytes, we used antibodies that specifically recognize phosphorylated $\beta$-catenin at serine 33 , serine 37 , and threonine 41 , and antibodies that recognize phosphorylated cyclin D1 at threonine 286, and studied whether KL treatment of cultured oocytes can lead to changes in levels of phosphorylated $\beta$-catenin and cyclin D1 accompanying the inactivation of GSK-3. However, our data showed that the phosphorylated $\beta$-catenin and cyclin D1 levels did not change upon KL treatment, suggesting that these two molecules may not be the immediate downstream effectors of GSK-3 in mouse oocytes.

Figure $6 \mathrm{KL}$ treatment of mouse oocytes does not alter the phosphorylation states of GS, p70S6 kinase, and mTOR. Oocytes were isolated from 8-day-old mice, starved, and stimulated with $150 \mathrm{ng} / \mathrm{ml}$ soluble $\mathrm{KL}$ for 2, 5, 10, and $30 \mathrm{~min}$, and the oocytes were then lysed for Western blot analysis as described in Materials and methods. Levels of phosphorylated GS ((A), (E)), phosphorylated p70S6 kinase $((B),(F))$, phosphorylated mTOR $((C),(G))$, and $\beta$-actin (D) in oocytes at different time points of $K L$ stimulation were found not to be significantly different $(P>0.05)$. 
Tau is another GSK-3 substrate that can be hyperphosphorylated at approximately 25 sites by GSK-3, and also by extracellular regulated kinase (ERK) and Cdk5 (Johnson \& Stoothoff 2004, Stoothoff \& Johnson 2005). Phosphorylation of Tau reduces its ability to bind to microtubules and destabilizes microtubules in Alzheimer's disease (Bramblett et al. 1993, Johnson \& Stoothoff 2004). A previous study has reported that in mouse oocytes, lithium chloride ( $\mathrm{LiCl})$, which inhibits both inositol monophosphatase and GSK-3, was found to cause abnormal spindle formation and increased incidence of abnormal homolog segregation during the first meiotic division (Wang et al. 2003). To determine whether Tau is a possible substrate of GSK-3 in growing mouse oocytes, we have started to study the expression of Tau and its phosphorylation by soluble KL in mouse oocytes. We have found that Tau is indeed expressed in mouse oocytes (unpublished data), and we are now in the process of studying whether Tau serves as a GSK-3 substrate in mouse oocytes, and if so, what the physiological consequences might be.

In summary, the present study has demonstrated that recombinant soluble KL can lead to phosphorylation/ inactivation of GSK- $3 \alpha$ and GSK-3 $\beta$ in cultured growing mouse oocytes, indicating that GSK-3 may participate in regulation of mammalian oocyte growth and early follicular development. However, the molecules downstream of GSK-3 in mouse oocytes remain to be identified. Future studies involving in-depth analysis of oocyte growth and follicular development in GSK-3 mutated mice, as well as screening for GSK-3 substrates in mouse oocytes, will give us a better understanding of the mechanisms by which GSK-3 regulates oocyte growth and follicular development.

\section{Acknowledgements}

The authors wish to thank Dr Dario Alessi (University of Dundee, UK) for providing the murine GSK- $3 \alpha$ cDNA. This work was supported by the Swedish Cancer Society (CF Project no. 4988-B04-01XAB), the Swedish Research Council (VR project no. K2005-72X-1537901A), the Swedish Cancer Research Foundation in Norrland (LP-05-1641, LP-05-1665), the Biotechnology Grant (Umeå, Sweden), and the Medical Faculty of Umeå University, Sweden. The authors declare that there is no conflict of interest that would prejudice the impartiality of this scientific work.

\section{References}

Albertini DF \& Barrett SL 2003 Oocyte-somatic cell communication. Reproduction Supplement 61 49-54.
Besmer P, Manova K, Duttlinger R, Huang EJ, Packer A, Gyssler C \& Bachvarova RF 1993 The kit-ligand (steel factor) and its receptor c-kit/W: pleiotropic roles in gametogenesis and melanogenesis. Development (Cambridge, England) Supplement 125-137.

Blume-Jensen P \& Hunter T 2001 Oncogenic kinase signalling. Nature $411355-365$

Bramblett GT, Goedert M, Jakes R, Merrick SE, Trojanowski JQ \& Lee VM 1993 Abnormal tau phosphorylation at Ser396 in Alzheimer's disease recapitulates development and contributes to reduced microtubule binding. Neuron 10 1089-1099.

Cadigan KM \& Nusse R 1997 Wnt signaling: a common theme in animal development. Genes and Development 11 3286-3305.

Cross DA, Alessi DR, Cohen P, Andjelkovich M \& Hemmings BA 1995 Inhibition of glycogen synthase kinase- 3 by insulin mediated by protein kinase B. Nature 378 785-789.

Diehl JA, Cheng M, Roussel MF \& Sherr CJ 1998 Glycogen synthase kinase-3beta regulates cyclin D1 proteolysis and subcellular localization. Genes and Development 12 3499-3511.

Driancourt MA, Reynaud K, Cortvrindt R \& Smitz J 2000 Roles of KIT and KIT LIGAND in ovarian function. Reviews of Reproduction 5 143-152.

Elvin JA \& Matzuk MM 1998 Mouse models of ovarian failure. Reviews of Reproduction 3 183-195.

Eppig JJ 2001 Oocyte control of ovarian follicular development and function in mammals. Reproduction 122 829-838.

Ferrer I, Gomez-Isla T, Puig B, Freixes M, Ribe E, Dalfo E \& Avila J 2005 Current advances on different kinases involved in tau phosphorylation, and implications in Alzheimer's disease and tauopathies. Current Alzheimer Research 2 3-18.

Fingar DC, Salama S, Tsou C, Harlow E \& Blenis J 2002 Mammalian cell size is controlled by mTOR and its downstream targets $\mathrm{S} 6 \mathrm{~K} 1$ and 4EBP1/eIF4E. Genes and Development 16 1472-1487.

Horie K, Takakura K, Taii S, Narimoto K, Noda Y, Nishikawa S, Nakayama H, Fujita J \& Mori T 1991 The expression of c-kit protein during oogenesis and early embryonic development. Biology of Reproduction 45 547-552.

Ismail RS, Okawara Y, Fryer JN \& Vanderhyden BC 1996 Hormonal regulation of the ligand for c-kit in the rat ovary and its effects on spontaneous oocyte meiotic maturation. Molecular Reproduction and Development 43 458-469.

Johnson GV \& Stoothoff WH 2004 Tau phosphorylation in neuronal cell function and dysfunction. Journal of Cell Science $1175721-5729$.

Kissel H, Timokhina I, Hardy MP, Rothschild G, Tajima Y, Soares V, Angeles M, Whitlow SR, Manova K \& Besmer P 2000 Point mutation in kit receptor tyrosine kinase reveals essential roles for kit signaling in spermatogenesis and oogenesis without affecting other kit responses. EMBO Journal 19 1312-1326.

Laitinen M, Rutanen EM \& Ritvos O 1995 Expression of c-kit ligand messenger ribonucleic acids in human ovaries and regulation of their steady state levels by gonadotropins in cultured granulosaluteal cells. Endocrinology 136 4407-4414.

Liu K 2006 Stem cell factor (SCF)-kit mediated phosphatidylinositol 3 (PI3) kinase signaling during mammalian oocyte growth and early follicular development. Frontiers in Bioscience 11 126-135.

Liu L, Rajareddy S, Reddy P, Jagarlamudi K, Shen Y, Gunnarsson D, Boman K \& Liu K 2006 Infertility caused by follicular development retardation in mice with oocyte-specific expression of Foxo3a. Development. In press.

Manova K, Nocka K, Besmer P \& Bachvarova RF 1990 Gonadal expression of c-kit encoded at the W locus of the mouse. Development 110 1057-1069.

Manova K, Huang EJ, Angeles M, De LV, Sanchez S, Pronovost SM, Besmer P \& Bachvarova RF 1993 The expression pattern of the c-kit ligand in gonads of mice supports a role for the c-kit receptor in oocyte growth and in proliferation of spermatogonia. Developmental Biology 157 85-99. 
Matzuk MM, Burns KH, Viveiros MM \& Eppig JJ 2002 Intercellular communication in the mammalian ovary: oocytes carry the conversation. Science 296 2178-2180.

McGee EA \& Hsueh AJ 2000 Initial and cyclic recruitment of ovarian follicles. Endocrine Reviews 21 200-214.

Nilsson E \& Skinner MK 2001 Cellular interactions that control primordial follicle development and folliculogenesis. Journal of the Society for Gynecologic 8 S17-S20.

Nusse R 1997 A versatile transcriptional effector of wingless signaling. Cell 89 321-323.

Orr-Urtreger A, Avivi A, Zimmer Y, Givol D, Yarden Y \& Lonai P 1990 Developmental expression of c-kit, a proto-oncogene encoded by the W locus. Development 109 911-923.

Polakis P 1999 The oncogenic activation of beta-catenin. Current Opinion in Genetics and Development 9 15-21.

Reddy P, Shen L, Ren C, Boman K, Lundin E, Ottander U, Lindgren P, Liu YX, Sun QY \& Liu K 2005 Activation of Akt (PKB) and suppression of FKHRL1 in mouse and rat oocytes by stem cell factor during follicular activation and development. Developmental Biology 281 160-170.

Richards JS, Russell DL, Ochsner S, Hsieh M, Doyle KH, Falender AE, Lo YK \& Sharma SC 2002 Novel signaling pathways that control ovarian follicular development, ovulation, and luteinization. Recent Progress in Hormone Research 57 195-220.

Schaeren-Wiemers N \& Gerfin-Moser A 1993 A single protocol to detect transcripts of various types and expression levels in neural tissue and cultured cells: in situ hybridization using digoxigeninlabelled cRNA probes. Histochemistry 100 431-440.

Srivastava AK \& Pandey SK 1998 Potential mechanism(s) involved in the regulation of glycogen synthesis by insulin. Molecular and Cellular Biochemistry 182 135-141.

Stoothoff WH \& Johnson GV 2005 Tau phosphorylation: physiological and pathological consequences. Biochimica et Biophysica Acta 1739 280-297.
Vanderhyden B 2002 Molecular basis of ovarian development and function. Frontiers in Bioscience 7 d2006-d2022.

Villar-Palasi C \& Guinovart JJ 1997 The role of glucose 6-phosphate in the control of glycogen synthase. FASEB Journal 11 544-558.

Vlahos CJ, Matter WF, Hui KY \& Brown RF 1994 A specific inhibitor of phosphatidylinositol 3-kinase, 2-(4-morpholinyl)-8-phenyl-4H-1benzopyran-4-one (LY294002). Journal of Biological Chemistry 269 $5241-5248$.

Voytyuk O, Lennartsson J, Mogi A, Caruana G, Courtneidge S, Ashman LK \& Ronnstrand L 2003 Src family kinases are involved in the differential signaling from two splice forms of c-Kit. Journal of Biological Chemistry 278 9159-9166.

Wang X, Liu XT, Dunn R, Ohl DA \& Smith GD 2003 Glycogen synthase kinase-3 regulates mouse oocyte homologue segregation. Molecular Reproduction and Development 64 96-105.

Wassarman PM \& Albertini DF 1994 The mammalian ovum. In The Physiology of Reproduction, edn 2 Edn, pp 79-122. Eds E Knobil \& JD Neill. New York: Raven Press Ltd.

Welsh GI, Wilson C \& Proud CG 1996 GSK3: a SHAGGY frog story. Trends in Cell Biology 6 274-279.

Wodarz A \& Nusse R 1998 Mechanisms of Wnt signaling in development. Annual Review of Cell and Developmental Biology 14 59-88.

Yoshida H, Takakura N, Kataoka H, Kunisada T, Okamura H \& Nishikawa SI 1997 Stepwise requirement of c-kit tyrosine kinase in mouse ovarian follicle development. Developmental Biology 184 122-137.

Yost C, Torres M, Miller JR, Huang E, Kimelman D \& Moon RT 1996 The axis-inducing activity, stability, and subcellular distribution of beta-catenin is regulated in Xenopus embryos by glycogen synthase kinase 3. Genes and Development 10 1443-1454.

Received 15 June 2006

Accepted 1 August 2006 